\title{
Temperature dependent damping studies of Ni-Mn-Ga polymer composites
}

\author{
R SENTHUR PANDI, M MAHENDRAN*, R CHOKKALINGAM, M MANIVELRAJA ${ }^{\dagger}$ \\ and V CHANDRASHEKARAN ${ }^{\dagger}$ \\ Smart Materials Laboratory, Department of Physics, Thiagarajar College of Engineering, Madurai 625 015, India \\ ${ }^{\dagger}$ Advanced Magnetics Group, Defence Metallurgical Research Laboratory, Hyderabad 500 058, India
}

MS received 11 March 2010; revised 7 April 2010

\begin{abstract}
Mechanical properties of ferromagnetic shape memory alloy (FSMA) polyurethane (PU) polymer composites are studied using dynamic mechanical analysis (DMA) at different temperatures. The sample used in the study is $\mathrm{Ni}-\mathrm{Mn}-\mathrm{Ga} / \mathrm{PU}$ polymer composite. DMA studies reveal that the mechanical modulus decreases, when the temperature increases. The peak in internal friction $(\tan \delta)$ appears twice due to martensite transformation of the reinforced particles and glass transition of the polymer matrix. The strain is due to the motion of twin boundaries rather than the phase transformations. Twin boundary motion is found to be the root cause for the martensite-austenite transformation and vice versa, and leads to enhanced damping mechanism. Speculations on twin boundaries of this sample to show concrete evidence on change in internal friction $(\tan \delta$ ) are still underway. This paper proposes that $\mathrm{Ni}-\mathrm{Mn}-\mathrm{Ga} / \mathrm{PU}$ polymer composites can be used as efficient dampers.
\end{abstract}

Keywords. Smart materials; Ni-Mn-Ga; damping materials; vibration damping; dynamic mechanical analysis.

\section{Introduction}

Ferromagnetic shape memory alloys (FSMAs) are well known for their giant magnetic-field induced strain (MFIS), which make them potential candidates for applications such as actuators and sensors (Ullakko et al 1996; Chernenko et al 2007). It is evident from the literature that the FSMAs have ferromagnetic nature and undergo martensite transformation (Ullakko et al 1996; Mullner and Ullakko 1998; Mullner et al 2002; Chernenko et al 2007; Techapiesancharoenkij et al 2008). The phase transformation and energy dissipation through twin mechanism in $\mathrm{Ni}-\mathrm{Mn}-\mathrm{Ga}$ makes it a suitable candidate for dampers. There are lots of literature available for the structural, mechanical and magnetic studies for the NiMn-Ga FSMA (Segui et al 2004; Segui et al 2005; Chernenko et al 2007, Sanjay Singh et al 2010). The martensite transformations are the characteristics of $\mathrm{Ni}-$ $\mathrm{Mn}-\mathrm{Ga}$ that can be varied by changing the chemical compositions, which can lead to formation of a different group of alloys (Segui et al 2004).

The transformations that take place from the parent phase to the intermediate and then to martensite on cooling and heating of the FSMAs give enormous information on twin boundaries (Kokorin et al 1996; Segui et al 2004;

*Author for correspondence (manickam-mahendran@tce.edu)
Vijay Kumar Srivastava et al 2005; Segui et al 2005; Planes et al 2007). It has been reported that the motion of twin boundary is due to the application of magnetic field (Mullner and Ullakko 1998). Magnetic shape memory effect through MFIS is possible only if the magneto crystalline anisotropy energy is greater than the energy required to move the twin boundaries (Mullner and Ullakko 1998). The response and actuation capabilities of $\mathrm{Ni}-\mathrm{Mn}-\mathrm{Ga}$ are very quick and hence they can act as potential candidates for many engineering applications. The micromechanical approach considers the dislocation of twinning motion an elementary step of magneto plasticity. The domain rearrangement such as growth and shrinkage is controlled by the mobile twin boundaries (Mullner et al 2002). These types of transformations within the domain structure lead to an interesting study about the damping behavior. The damping behavior of these materials is very sensitive to the micro structural changes.

The advantages like high frequency performance and the large MFIS of Ni-Mn-Ga will be limited by its brittleness. In actuation applications, it needs a compressive loading to recover its original shape (Eric Gans and Greg Carman 2006). These disadvantages are partially overcome by embedding the $\mathrm{Ni}-\mathrm{Mn}-\mathrm{Ga}$ into the polymer matrix. There are several reports about the polymer matrix Ni-Mn-Ga composites by various research groups (Jorge Feuchtwanger et al 2003; Hideki Hosoda et al 
2004, Eric Gans and Greg Carman 2006; Aaltio et al 2007; Scheerbaum et al 2007; Xiaogang Sun and Chaoying Xie 2007). Cyclic actuation, vibration damping, magnetization in polymer composites, twin boundary movement in polymer composites and stress-strain studies for energy absorption applications have already been carried out (Jorge Feuchtwanger et al 2003, 2004, 2005; Eric Gans and Greg Carman 2006; Scheerbaum et al 2007; Lahelin et al 2009). The matrix materials such as polyurethane, epoxy, polyester, and silicone are chosen with desired stiffness for actuation and damping applications (Jorge Feuchtwanger et al 2003; Eric Gans and Greg Carman 2006; Yuanchang Liang et al 2006; Scheerbaum et al 2007; Xiaogang Sun and Chaoying Xie 2007; Lahelin et al 2009).

The Ni-Mn-Ga in the form of fibres, spark eroded powder, ball-milled powder and plates is analyzed for various composite studies (Jorge Feuchtwanger et al 2003; Hideki Hosoda et al 2004; Eric Gans and Greg Carman 2006; Scheerbaum et al 2007). It has been reported that the inclusion of $\mathrm{Ni}-\mathrm{Mn}-\mathrm{Ga}$ particle increases the loss ratio of the polymer material. The storage modulus of the $\mathrm{Ni}-\mathrm{Mn}-\mathrm{Ga} / \mathrm{PU}$ composite depends on the glass transition temperature of the polymer (Lahelin et al 2009). The damping ability of $\mathrm{Ni}-\mathrm{Mn}-\mathrm{Ga}$ composite is enhanced by the polymer material's viscous force and the ductility (Jorge Feuchtwanger et al 2004, 2005; Yuanchang Liang et al 2006; Aaltio et al 2007, Muhammad Yasar Razzaq et al 2007; Xiaogang Sun and Chaoying Xie 2007; Lahelin et al 2009).

The Ni-Mn-Ga epoxy composites having 40\% Ni-MnGa particle were reported to have higher modulus than pure epoxy because of the reinforcement of the martensite Ni-Mn-Ga particles and defects (voids) present in the composite (Xiaogang Sun and Charoying Xie 2007). This leads to a drastic decrease of modulus in the martensite transformation temperature and complicates the internal friction. The martensite transformation temperature of Ni-Mn-Ga particles is not affected by the polymer matrix in the composites (Lahelin et al 2009). The twin boundary motion is not elaborated in detail in $\mathrm{Ni}-$ $\mathrm{Mn}-\mathrm{Ga} / \mathrm{PU}$ composites in the previous works (Jorge Feuchtwanger et al 2003; Lahelin et al 2009). Whereas, here, by the use of spark eroded technique the Ni-Mn-Ga sample has been prepared in such a way that the twin boundary can be moved in a controllable way to study the mechanical properties. A few literatures are available on damping capacity of $\mathrm{Ni}-\mathrm{Mn}-\mathrm{Ga}$ polymer composites using dynamic mechanical analysis (DMA) (Aaltio et al 2007; Xiaogang Sun and Chaoying Xie 2007; Lahelin et al 2009). Polyurethane based matrix material has large stress-strain loops, which show that they have high damping capacity than other matrix materials do. Jorge Feuchtwanger et al have analyzed energy absorption and magnetic studies on the polyurethane $\mathrm{Ni}-\mathrm{Mn}-\mathrm{Ga} / \mathrm{PU}$ composites.
In the present paper, owing to the want of much needed scientific data on the $\mathrm{Ni}-\mathrm{Mn}-\mathrm{Ga} / \mathrm{PU}$ composites, a new material having good mechanical damping has been designed and developed. A composite of this kind has been chosen, as it is useful in potential applications like actuators and mechanical energy absorbing materials. Although the magnetic phase transition in the pre-stressed $\mathrm{Ni}-\mathrm{Mn}-\mathrm{Ga} / \mathrm{PU}$ composite has been reported (Jorge Feuchtwanger et al 2003), the loss ratio and modulus of these new materials are not reported. The phase transition temperature in response to the mechanical stress has been the query for many years for mechanical damper applications. However, to our knowledge the DMA studies on $\mathrm{Ni}-\mathrm{Mn}-\mathrm{Ga} / \mathrm{PU}$ polymer composites for damping application are not yet reported. In this paper, the studies on the mechanical and microstructure of $\mathrm{Ni}-\mathrm{Mn}-\mathrm{Ga} / \mathrm{PU}$ composites are presented based on the results derived from DMA and scanning electron microscope (SEM). In this paper, an insight is attempted into the subject by showing the relation between the elastic modulus and internal friction. The temperature effect in $\mathrm{Ni}-\mathrm{Mn}-\mathrm{Ga} / \mathrm{PU}$ composite has been observed with special reference to the twin boundary motion. We have used different $\mathrm{Ni}-\mathrm{Mn}-\mathrm{Ga} / \mathrm{PU}$ composites such as $20 \% \mathrm{Ni}-\mathrm{Mn}-\mathrm{Ga}$ in PU, 24\% Ni-Mn$\mathrm{Ga}$ in $\mathrm{PU}, 30 \% \mathrm{Ni}-\mathrm{Mn}-\mathrm{Ga}$ in $\mathrm{PU}$ and $36 \% \mathrm{Ni}-\mathrm{Mn}-\mathrm{Ga}$ in $\mathrm{PU}$, which are most suitable for mechanical energy absorption than other composites.

\section{Experimental}

The composite is prepared by mixing the polyurethane (PU) matrix and powder form of the Ni-Mn-Ga. For choosing the polymer matrix, we have followed some definite criteria i.e. the matrix should be stiff enough to produce sufficient stress in $\mathrm{Ni}-\mathrm{Mn}-\mathrm{Ga}$, curing time of the polymer should be optimum enough to align the particles and shrinkage of the polymer during curing should be minimum (Jorge Feuchtwanger et al 2003). Based on the above, it is recommended that PU can be used as an effective matrix for damping applications. Resin and hardner of Lord $7545 \mathrm{~A} / \mathrm{D}$ polyurethane are mixed using a gun and used as matrix material in the composites.

The spark-eroded powder of $\mathrm{Ni}-\mathrm{Mn}-\mathrm{Ga}$ is prepared under liquid nitrogen and obtained from the Magnetic Materials Group, MIT, USA. The composites are made by $24 \%$ volume of $\mathrm{Ni}-\mathrm{Mn}-\mathrm{Ga}$ powder where the volume percentage is optimized from the previous works (Jorge Feuchtwanger et al 2005). Although, 20\% Ni-Mn-Ga in $\mathrm{PU}, 24 \% \mathrm{Ni}-\mathrm{Mn}-\mathrm{Ga}$ in PU, 30\% Ni-Mn-Ga in PU and $36 \% \mathrm{Ni}-\mathrm{Mn}-\mathrm{Ga}$ in $\mathrm{PU}$ composites have been prepared for our investigations, only $24 \% \mathrm{Ni}-\mathrm{Mn}-\mathrm{Ga}$ in PU has been optimized for this work. The Ni-Mn-Ga powder is mixed with the slurry and then placed in a Teflon mold to get the sample for DMA study. The size of the sample used in the study is $15 \mathrm{~mm} \times 2 \mathrm{~mm} \times 5 \mathrm{~mm}$. The compo- 


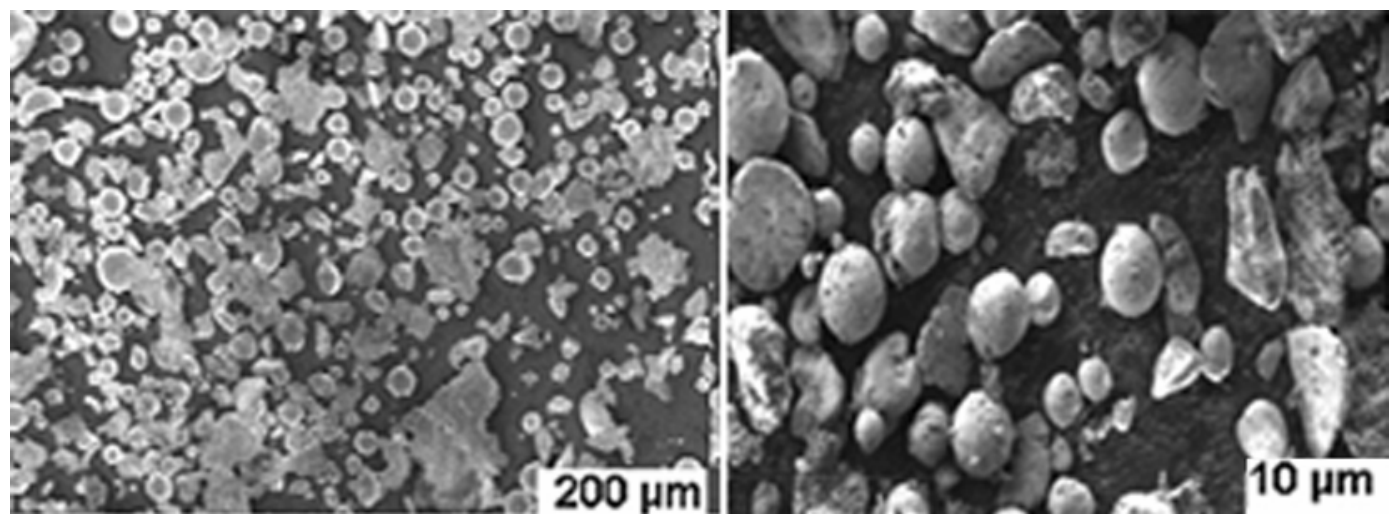

Figure 1. The microstructure of $\mathrm{Ni}-\mathrm{Mn}-\mathrm{Ga} / \mathrm{PU}$ polymer composites. The structural alignment of the $\mathrm{Ni}-\mathrm{Mn}-\mathrm{Ga}$ particles embedded in the polymer matrix. The grey matrix shows the polymer material.

site is cured under a magnetic field of 4 KOe for particle alignment in the slurry matrix. The easy magnetic axis of $\mathrm{Ni}-\mathrm{Mn}-\mathrm{Ga}$ is ordered by magnetic curing which leads to the alignment of twin boundaries inside the composite.

Microstructural studies of the composite are performed on the sample to identify their alignment using Zeiss SEM. The damping properties of the Ni-Mn-Ga/PU composites are studied mainly with Perkin-Elmer DMA7. A three point bending configuration has been used for this study. Composite samples are heated at the rate of $5 \mathrm{~K} / \mathrm{min}$. The experiment is carried out with $3.5 \mathrm{MPa}$ stress amplitude at $1 \mathrm{~Hz}$ frequency range.

\section{Results and discussion}

Figure 1 shows the SEM image of the Ni-Mn-Ga/PU polymer composites. The $\mathrm{Ni}-\mathrm{Mn}-\mathrm{Ga}$ particles embedded in the polymer matrix are identified by their spherical shape. The grey matrix in the figure 1 shows the polymer material. The particles of different shapes and sizes are close to each other at $200 \mu \mathrm{m}$ magnification. The size of the particles is roughly estimated to be less than $10 \mu \mathrm{m}$. At higher magnification, the distance between the particles is clearly notable and the interaction between the particles is very less. It is expected that the curing process will make a chain-like alignment.

$\mathrm{Ni}-\mathrm{Mn}-\mathrm{Ga} / \mathrm{PU}$ composites are visco elastic materials in which the loss occurs due to relaxation process of the polymer chains when they are stretched and also due to the presence of $\mathrm{Ni}-\mathrm{Mn}-\mathrm{Ga}$ particles. $\mathrm{Ni}-\mathrm{Mn}-\mathrm{Ga} / \mathrm{PU}$ polymer composite possess complex Young's modulus, and their loss ratio is frequency dependent near the relaxation peaks. In this work, the temperature dependence of modulus and internal friction were studied. Some of the important parameters associated with the composite materials such as elastic modulus and $\tan \delta$ are obtained using dynamic mechanical analyzer. Ni-Mn-Ga acts as a filler particle in which the easy magnetization axes are partially oriented because of curing. It is obvious that when stress is applied to the sample, strain is generated in the composites. This could be accommodated within the region of $\mathrm{Ni}-\mathrm{Mn}-\mathrm{Ga}$ particles at the cost of other twin boundaries (Jorge Feuchtwanger et al 2003). The martensite transformation temperature of $\mathrm{Ni}-\mathrm{Mn}-\mathrm{Ga}$ has an impact on the elastic modulus of $\mathrm{Ni}-\mathrm{Mn}-\mathrm{Ga} / \mathrm{PU}$ composites. It has been observed that the polymer matrix has a broad peak in the internal friction near the glass transition temperature of the PU (Muhammad Yasar Razzaq et al 2007). The broad cooling curve is obtained in the temperature range between $0-75^{\circ} \mathrm{C}$. On the other hand, the heating curve is obtained from $25-100^{\circ} \mathrm{C}$. These broad peaks are due to softening of the polymer. The temperature difference between the peaks during the heating and cooling processes is due to the temperature dependence of martensite twinning stress (Segui et al 2005).

Figure 2 shows the internal friction as well as damping capability of the $\mathrm{Ni}-\mathrm{Mn}-\mathrm{Ga} / \mathrm{PU}$ composite. Muhammad Yasar Razzaq et al reported that damping capabilities of polyurethane show the maximum internal friction at 0.6 $\tan \delta$. It is in good agreement with the matrix material. The peaks occur at low temperatures $\left(-125^{\circ} \mathrm{C}\right.$ to $\left.0^{\circ} \mathrm{C}\right)$, in particular, a small peak occurs at $-50^{\circ} \mathrm{C}$ showing the origin of internal friction. It is because of the $\mathrm{Ni}-\mathrm{Mn}-\mathrm{Ga}$ softening during phase transformation. These peaks reveal the reinforcement of the martensite $\mathrm{Ni}-\mathrm{Mn}-\mathrm{Ga}$ particles in the polymer matrix. The broader peak indirectly shows inhomogeneity of the particle inside the composite. Usually the sharp internal friction peak occurs in single crystals due to their high order homogeneity. It is observed that internal friction is higher in cooling than in heating process. It shows that particles are more compressed during cooling.

Stress-induced twin boundary motion within $\mathrm{Ni}-\mathrm{Mn}-$ Ga particles enhances the damping properties of the NiMin-Ga/PU composites. The decrease of internal friction with reduction in temperature reflects the decreasing 
mobility of twin boundaries (Eric Gans and Greg Carman 2006; Scheerbaum et al 2007). When the twin boundary movement is increased, the damping capacity of the composites will be enhanced.

Figure 3 shows the elastic modulus changes occurring in the composite at various temperatures. During heating, the elastic modulus shows two stages of drop. The first drop is due to the $\mathrm{Ni}-\mathrm{Mn}-\mathrm{Ga}$ phase transformation and the second one is due to polymer glass transition temperature. Similarly, in the case of cooling, the curve rises in two stages. The changes in elastic modulus at the transformation temperature indirectly reveals the micro structural nature of the $\mathrm{Ni}-\mathrm{Mn}-\mathrm{Ga}$ particles. The low elastic modulus in the austenite phase shows the absence of twins, which results in low damping in the austenite phase of the material. The magnetic transitions do not

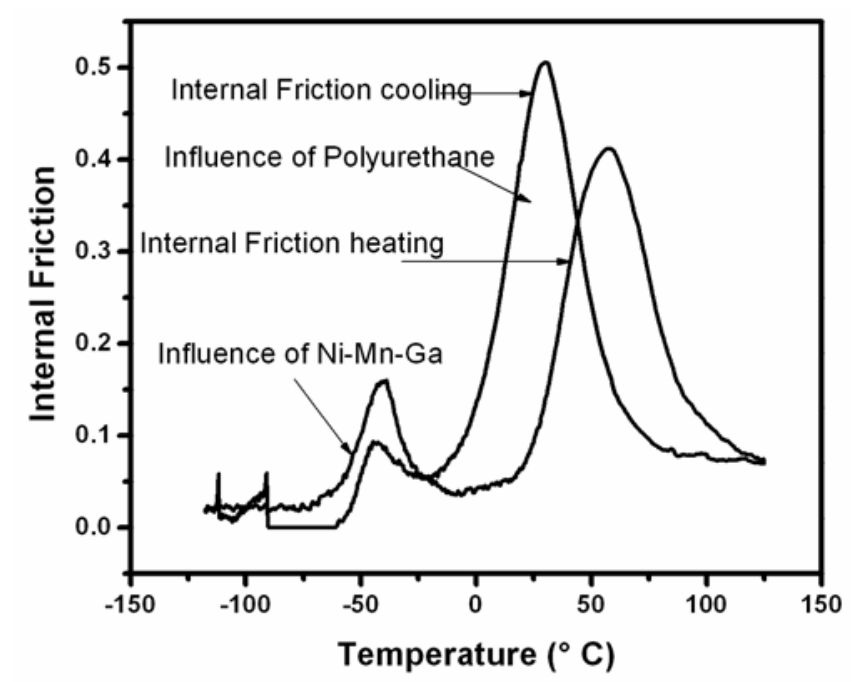

Figure 2. Internal friction at various temperatures

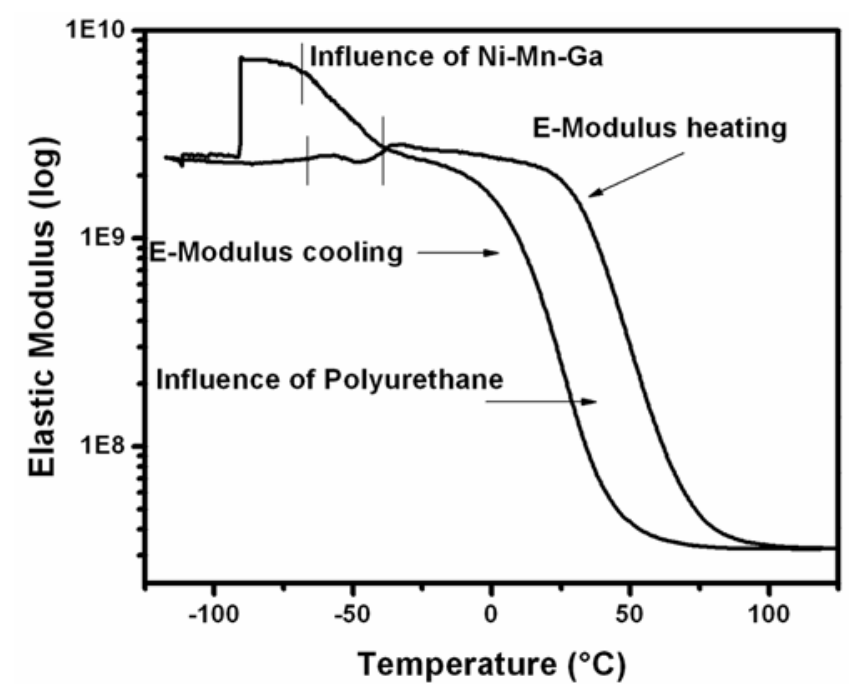

Figure 3. Changes in elastic modulus in the composite at various temperatures. show any impact in the DMA graph. It is due to the low magnetic hysteresis of $\mathrm{Ni}-\mathrm{Mn}-\mathrm{Ga}$.

\section{Conclusions}

Using the DMA, temperature dependent damping of $\mathrm{Ni}$ $\mathrm{Mn}-\mathrm{Ga} / \mathrm{PU}$ composites were studied, which confirms that the polyurethane matrix allows the twin movement in the $\mathrm{Ni}-\mathrm{Mn}-\mathrm{Ga}$ particles. Whenever the phase transformation temperature of the particle and glass transition temperature of the matrix matches, the composite shows enhanced damping capabilities. It is proposed that this polymer composite can be an effective absorbing material for vibration damping applications. More mechanical testing methods will throw some light on the optimization of the damping performance of the $\mathrm{Ni}-\mathrm{Mn}-\mathrm{Ga} / \mathrm{PU}$ polymer composites.

\section{Acknowledgements}

M M thanks Dr Robert C O Handley for his scholarly guidance and introducing him to the subject and also Dr Jorge Feuchtwanger for his suggestions in preparing composite samples. The authors thank Prof. Eduard Cesari and Dr Segui for helping in DMA measurements. Financial support from DRDO (0704383) is greatly acknowledged.

\section{References}

Aaltio I, Lahelin M, Soderberg O, Heczko O, Lofgren B, Ge Y, Seppala J and Hannula S P 2007, Mater. Sci. Eng. A481-482 314

Chernenko V A, Besseghini S, Müllner P and Kostorz G 2007 Sensor Letts. 5229

Eric Gans and Greg P Carman 2006 J. Appl. Phys. 99084905

Hideki Hosoda, Shinsuke Takeuchi, Tomonari Inamura and Kenji Wakashima 2004 Sci. Tech. Adv. Mater 5503

Jorge Feuchtwanger, Kelli Griffin, Jiankang Huang, David Bono, Robert C O Handley and Samuel M Allen 2004 J. Magn. Magn. Mater. 272-276 2038

Jorge Feuchtwanger, Marc L Richard, Yun J Tang, Ami E Berkowitz, Robert C O Handley and Samuel M Allen 2005 J. Appl. Phys. 97 10M319-1

Jorge Feuchtwanger, Sadie Michael, Jiankang Huang, David Bono, Robert C O Handley, Samuel M Allen and Catherine Jenkins 2003 J. Appl. Phys. 938528

Kokorin V V, Chernenko V A, Cesari E, Pons J and Segui C 1996 J. Phys. Condens. Matter 86457

Lahelin M, Aaltio I, Heczko O, Soderberg O, Ge Y, Lofgren B, Seppala J and Hannula S P 2009 Composites: Part A $\mathbf{4 0}$ 125

Muhammad Yasar Razzaq, Mathias Anhalt, Lars Frormann and Bernd Weidenfeller 2007 Mater. Sci. Eng. A471 57

Mullner P, Chernenko V A, Wollgarten M and Kostorz G. 2002 J. Appl. Phys. 926708

Mullner P and Ullakko K 1998 Phys. Stat. Sol. (b) 208 R1 
Planes A, Manosa L, Moya X, Krenke T, Acet M and Wassermann E F 2007 J. Magn. Magn. Mater. 3102767

Sanjay Singh, Bhardwaj S, Panda A K, Ahire V K, Mitra A, Awasthi A M and Barman S R 2010 Mater. Sci. Forum 63543

Scheerbaum N, Hinz D, Gutfleisch O, Muller K H and Schultz L 2007 Acta. Mater. 552707

Segui C, Cesari E, Pons J and Chernenko V A 2004 Mater. Sci. Eng. A370 481

Segui C, Chernenko V A, Pons J, Cesari E, Khovailo V and Takagi T 2005 Acta. Mater. 53111
Techapiesancharoenkij R, Kostamo J, Simon J, Bono D, Allen S M and O'Handley R C 2008 Appl. Phys. Lett. 92 032506-1

Ullakko K, Huang J K, Kantner C and O'Handley R C 1996 Appl. Phys. Lett. 691966

Vijay Kumar Srivastava, Ratnamala Chatterjee, Nigam A K and O’Handley R C 2005 Solid State Commun. 136297

Xiaogang Sun and Chaoying Xie 2007 Mater. Sci. Forum 561565697

Yuanchang Liang, Yauso Luga and Minoru Taya 2006 Sensors Actuators A125 512 